\title{
Protein tyrosine phosphatases: characterization of extracellular and intracellular domains
}

\author{
Robert J Mourey and Jack E Dixon
}

\author{
University of Michigan, Ann Arbor, USA
}

\begin{abstract}
Protein tyrosine phosphatases (PTPs) play an important role in the regulation of cell growth and differentiation. With over 30 PTPs identified, the specific functions of these enzymes are now being addressed. The identification of extracellular domain receptor-like PTP interactions and the characterization of intracellular PTP 'targeting' domains represent recent efforts in this pursuit.
\end{abstract}

Current Opinion in Genetics and Development 1994, 4:31-39

\section{Introduction}

The importance of protein tyrosine phosphorylation in growth, differentiation and cytoskeletal integrity has been well established over the past decade. Protein tyrosine phosphatases (PTPs), enzymes that hydrolyze phosphotyrosyl groups, were initially considered to play 'housekeeping' roles by returning the tyrosine phosphorylation state of target substrates back to basal levels. This overly simplistic view now seems to be incorrect, since a number of PTP's have been shown to regulate integral components of signal transduction pathways (for recent reviews, see $\left[1^{\bullet \bullet}, 2^{\bullet}, 3^{\bullet \bullet}\right]$ ). PTPs have been implicated in tumor suppression $\left[4,5,6^{\bullet}, 7-9\right]$, cytoskeletal reorganization $\left[10^{\bullet \bullet}, 11^{\bullet}\right]$, development and differentiation $\left[12^{\bullet \bullet}, 13,14^{\bullet \bullet}\right]$, mitotic induction $\left[15^{\circ}, 16,1^{\circ}\right]$, T-cell activation [18 $]$, and in

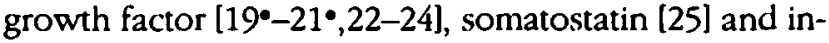
terferon $\left[26^{\bullet \bullet}, 27^{\bullet}\right]$ signaling pathways. This review will focus on recent advances in understanding the function of receptor-like PTP extracellular domains, as well as the role of specific 'zip code' domains that govern intracellular PTP subcellular localization.

\section{Protein tyrosine phosphatase structural domains}

PTPs can be separated into two major groups: transmembrane receptor-like PTPs (Fig. 1), and intracellular PTPs (Fig. 2). All PTPs possess at least one catalytic domain of approximately 250 amino acids which contains the 'active site' signature motif (I/V)HCXAGXXR(S/T)G (in the one-letter amino acid code, where $\mathrm{X}$ can be any amino acid) $\left[3^{\bullet \bullet}, 28^{\circ}\right]$. Studies using chemical modification and site-directed mutagenesis have established that the cysteinyl residue within this consensus motif is essential for phosphatase activity, forming a thiophosphate enzyme intermediate necessary for catalysis [29]. This catalytic domain is unique to PTPs, bearing little resemblance to the catalytic domains of serine/threonine protein phospahatases, alkaline protein phosphatases, or acid protein phosphatases.

The receptor-like PTPs (Fig. 1) possess an extracellular domain, a single transmembrane domain, and usually two intracellular PTP catalytic domains. The first intracellular PTP domain generally accounts for the majority of catalytic activity, while the second domain is inactive or (in some cases) weakly active [30']. The only transmembrane PTPs containing a single catalytic domain are human (H) PTP $\beta$ and Drosophila (D) PTP10D [31-33]. Receptor-like PTP's can be further subdivided into five types on the basis of common features found in the extracellular domain [1*0]. Type $I$ is represented by the CD45 family, exhibiting multiple isoforms arising from differential splicing of sequences at the amino terminus [34]. Type II members (e.g. LAR, HPTPK, and HPTP $\mu$ ) contain tandem repeats of immunoglobulinlike and fibronectin type III-like domains resembling neural cell adhesion molecules [35,36,37 $7^{\circ}$. Type III members bear multiple fibronectin type III-like repeats (e.g. DPTP10 and DPTP99A) [32,33,38]. HPTP $\alpha$ and HPTPE represent type IV isoforms, possessing small glycosylated segments $[31,39]$. Type V constituents include HPTP $\zeta$ and RPTP $\gamma$, which exhibit amino-terminal carbonic anhydrase-like domains $[40,41 \cdot]$. Although the structural features of the receptor-like PTPs suggest that they may bind ligands, no 'ligand' interaction has yet been identified. However, the extracellular domain of a receptor-like PTP has recently been shown to mediate cell-cell aggregation via homophilic binding $\left[42^{\bullet \bullet}, 43^{\bullet \bullet}\right]$.

\footnotetext{
Abbreviations

CA — carbonic anhydrase; CAM_cellular adhesion molecule; EGF-epidermal growth factor; D-Drosophila; GFR-growth factor receptor; H-human; LAR-leukocyte common antigen related molecule;

MAP kinase-mitogen-activated protein kinase; PEST_proline-, glutamic acid-, serine- and threonine-rich; PTK_-protein tyrosine kinase; PTP-protein tyrosine phosphatase; SH2-Src homology 2; TCR-T-cell receptor.
} 


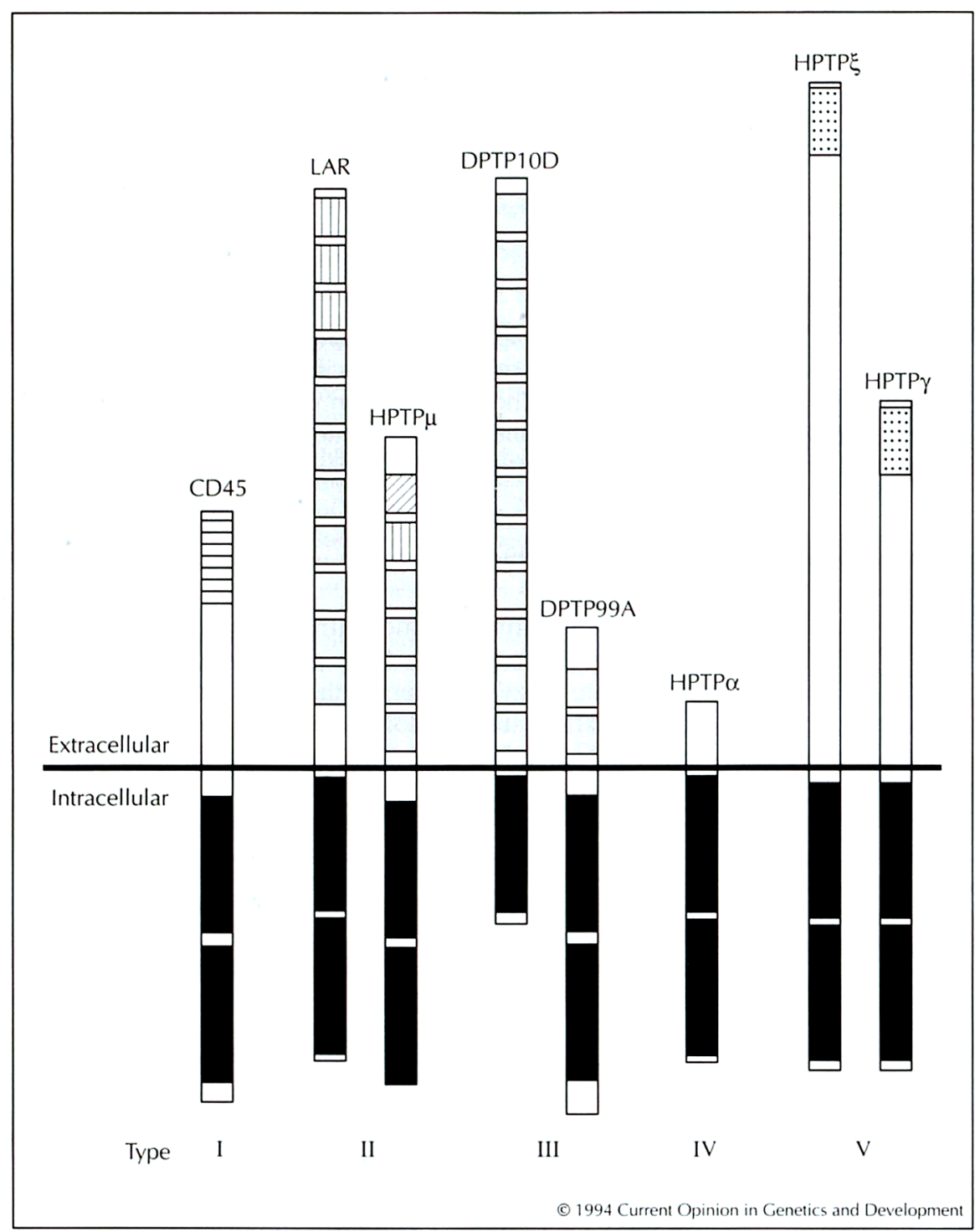

fig. 1. Transmembrane receptor-like PTPs. The members of this family of PTPs possess a single transmembrane domain, and one or two intracellular PTP catalytic domains (black bar). They can be subdivided into five types on the basis of their extracellular domain structures: I, for example CD45; II, for example LAR and HPTP $\mu$; III, for example DPTP10D and DPTP99A; IV, for example HPTP $\alpha$; and $V$, for example HPTP $\zeta$ and HPTPy [1*0]. The extracellular domain structures are shown: amino terminus isoforms (horizontal lines) resulting from differential splicing; immunoglobulin-like (vertical lines); fibronectin type III-like (shaded bar); MAM adhesive protein homology-like (diagonal lines); and carbonic anhydrase-like (stippled).
Intracellular PTPs (Fig. 2) possess a single catalytic domain with flanking regions that often contain amino acid sequences which direct the enzyme to specific intracellular locations. These zip code sequences can target PTPs to the endoplasmic reticulum (e.g. PTP1B) $\left[44,45^{\circ}\right]$, to the nucleus (e.g. DPTP61F) $\left[46^{\circ}{ }^{\circ}\right]$, or perhaps result in their rapid degradation (e.g. PTP-PEST) [47 $7^{\circ}$. Several amino-terminal structural motifs have been identified that may direct intracellular PTPs to interact with cytoskeletal proteins (e.g. HPTPMeg1, HPTPH1) $[48,49]$ or with phosphotyrosine-containing proteins via Src homology 2 (SH2) domains (e.g. PTP1C, SH-PTP2) [50,51॰].

\section{Transmembrane protein tyrosine phosphatases and extracellular domain interactions}

\section{CD45}

The receptor-like structure of transmembrane PTPs suggests that they may interact with ligands. CD45, the first transmembrane P'TP to be identified [34], has served as a model for understanding the function of the receptor-like PTPs. CD45 plays a role in T-cell receptor (TCR) mediated signal transduction and has been shown to reconstitute TCR signaling in CD45-deficient $T$ cells $\left[18^{\circ}, 52\right]$. In an effort to determine whether the extracellular domain of CD45 influences its function in TCR signal transduction, Desai et al. [53*•] constructed a chimera of the epidermal growth factor (EGF) receptor extracellular domain and the CD45 intracellular domain. The expression of this chimera in CD45-deficient T-cells restored TCR signal transduction (measured as intracellular calcium flux), indicating that the extracellular domain of CD45 is not absolutely required for TCR signaling. When EGF was added, TCR signaling was inhibited. The coexpression of a truncated EGF receptor (missing its cytoplasmic domain) with the EGF receptor/CD 45 chimera restored TCR signaling. This suggests that the chimera may dimerize on addition of EGF, resulting in inactivation of intracellular PTP activity. Expression of sufficient truncated EGF receptor would presumably prevent chimera self-as- 


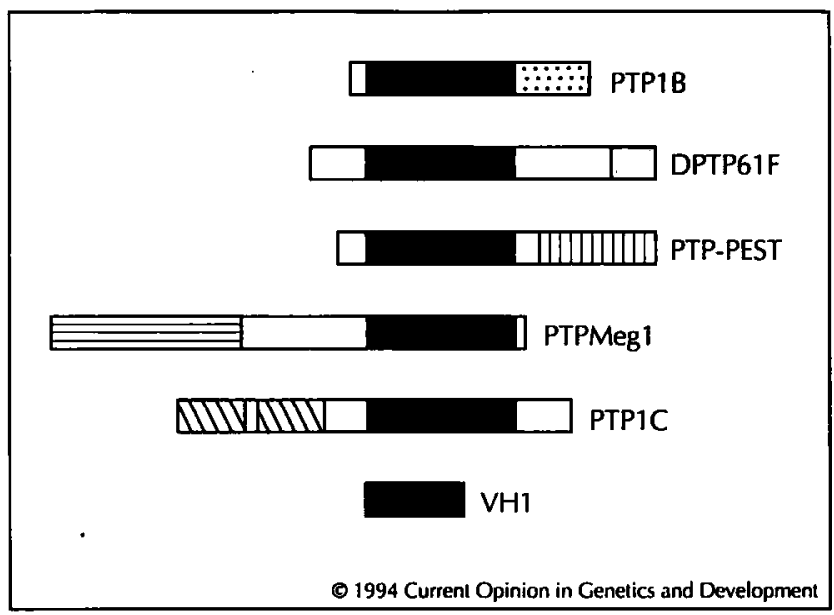

Fig. 2. Intracellular PTPs. The members of this family of PTPs possess a single catalytic domain (black bar) with flanking regions that often contain intracellular 'targeting' domains. Carboxy-terminal domains can target PTPs to the endoplasmic reticulum (stippled) for PTP 1B, to the nucleus (shaded box) for DPTP6IF, or result in their rapid degradation (vertical lines) for PTP-PEST. Amino-terminal domains may direct PTPs to interact with cytoskeletal proteins (horizontal lines) for PTPMeg1, or with phosphotyrosine via SH2 domains (diagonal lines) for PTP1C.

sociation. Data have also been published suggesting that CD45 is tyrosine-phosphorylated following TCR activation [54]. The specific effects of phosphorylation are unknown. It has been proposed that endogenous ligand-induced dimerization of CD45 may lead to transdephosphorylation and functional inactivation, analogous to the dimerization, transphosphorylation and activation of receptor protein tyrosine kinases (PTKs) [55].

Cell adhesion molecule-like protein tyrosine phosphatases Type II receptor-like PTT's share extracellular domain similarities to cell adhesion molecules (CAMs). PTTP $\mu$ and ${ }^{P T P K}$ contain one immunoglobulin-like domain and four fibronectin type III repeats [36,37\%]. In addition, they both contain an 'MAM' (meprin, A5, $\mu$ ) motif amino-terminal to the immunoglobulin-like domain. MAM motifs span approximately 170 amino acids and contain four conserved cysteines that may form disulficle bridges [56"]. The function of this domain is unknown. However, the MAM motif occurs in several diverse transmembrane adhesion proteins (e.g. A5 and meprin) and may therefore contribute 'adhesive' properties to PTP $\mu$ and PTI'K.

The sequence similarity of type II PTI's to CAMs has led researchers to suggest that these PTI's also promote homophilic binding. Expression of full-length $P T P \mu$ in SF9 insect cells results in cell aggregation, suggesting that $\mathrm{PTT}^{\prime} \mu$ may mediate this process $\left[42^{\bullet \bullet}, 43^{\bullet \bullet}\right]$. The expression of cytoplasmic domain-deleted constructs indicates that PTP catalytic activity is not required for the observed adhesion; only the extracellular domain is essential for cell-cell interactions. This was further substantiated by the observation that purified extracel- lular domain conjugated to resin beads can mediate bead-bead adhesion. Work from Schlessinger's laboratory, reported in a 'research news' article in Science [5700], indicates that the closely related molecule PTPK also displays homophilic adhesive properties [57 ${ }^{\circ}$ ]. When cells expressing PTP $\mu$ are mixed with cells expressing PTPK, the cells segregate and adhere in a homophilic fashion. This shows that although PTP $\mu$ and PTPK are structurally very similar, they display a high degree of specificity in their cell-cell adhesion. In addition, structurally similar LAR is not known to undergo homophilic interactions.

\section{Carbonic anhydrase-like protein tyrosine phosphatases}

Type V transmembrane PTPs contain a carbonic anhydrase (CA)-like domain in the amino-terminal 300 amino acids of their extracellular domain. These PTPs include the neural-specific human PTP $\zeta$ [40], mouse RPTP $\beta$ [58'], rat PTP18 (159]; RJ Mourey, KL Guan, unpublished data), and RPTPy [41.], which is expressed in kidney, brain and lung. The CA domains of these PTI's are $25-40 \%$ identical to the seven isotypes of CA. It is unlikely that this domain functions as a carbonic anhydrase, since two of the three essential histidyl residues required for catalysis are missing. Rather, the overall structure of the CA domain may be utilized for ligand binding. Indeed, computer modeling of this domain and comparison with the crystal structure of $\mathrm{CA}$ indicates that 11 of the 19 residues that form the active site of $\mathrm{CA}$ are conserved [ $\left.41^{\circ}\right]^{\circ}$. Interestingly, the type V PTPs show the same degree of identity to CA as does the vaccinia virus transmembrane protein D8 over almost its entire external domain, lacking two of the three catalytically required histidines [60]. Evidence suggests that the function of D8 is adsorption of the vaccinia virus to cell surfaces [61]. The shared homology between vaccinia $\mathrm{D} 8$ and this subclass of PTP's suggests that the D8 binding site may be a potential ligand for these PTPs.

\section{Targeting of intracellular protein tyrosine phosphatases to specific subcellular locations}

\section{SH2 domains}

The Src homology 2 (SH2) domain is a conserved sequence motif of approximately 100 amino acids that promotes interactions between cytoplasmic signaling molecules and specific phosphotyrosyl residues on activated (i.e. autophosphorylated) growth factor receptors or other signaling molecules. These interactions bring the appropriate signaling components of mitogenic pathways together $\left[62^{\bullet \bullet}, 63^{\bullet}, 64\right]$. Over the past two years, several new PTI's that contain two SH2 domains in their amino-terminal regions have been identified. These include PTP1C [50] and its homologs (SH-PTP1 [65], HCP [66] and SHP [67]), which are expressed predominantly in hematopoietic cells. More ubiquitously expressed SH2-containing PTPs include 
SH-PTP2 [51॰] and its homologs (Syp [68॰], PTP1D [69॰.), PTP2C [70], and SH-PTP3 [71]).

Evidence that these SH2-P'TPs may play a role in signal transduction comes from the characterization of two developmental genes, $H c p b\left[14^{\circ *}, 72\right]$ and corkscrew (csiv) [73"*]. Mice homozygous for the recessive allelic mutation motbeaten display severe hematopoietic abnormalities $\left[14^{\bullet \bullet}, 72\right]$. These mutations were recently localized to the $H c p h$ gene, which encodes the SH2-containing I'T' hematopoietic cell protein phosphatase [66]. Abnormalities in this protein may lead to defective signaling in hematopoiesis. Further evidence for the role of SH2-PTPs in signal transduction is provided by the Drosopbila gene $c s w$. This gene encodes an SH2-PTP that functions in the terminal class signal transduction pathway essential for normal development of anterior and posterior segments of the Drosophila embryo [730. . Genetic experiments suggest that csw interacts with polebole (the Drosophila homolog of c-raf) [74] to transduce signals generated from the receptor PTK torso (a PDGF receptor homo$\log$ [ [75]. The csw protein has high sequence identity with SH-PTP2 and may share functional similarities as well [76॰].

The exact nature of the interaction of SH2-containing PTPs with PTKs to positively transduce signals is unclear, although several possible models have been suggested [76*]. One possibility is that the amino-terminal SH2 domain of the PTP binds an activated growth factor receptor (GFR), allowing the second SH2 domain to bind other phosphotyrosyl proteins. In this way, the PTP is acting to bring proteins to the GFR for further phosphorylation, or to participate in other protein-protein interactions. In an alternative model, SH2-binding of PTPs to GFRs may allow the PTP to dephosphorylate nearby phosphotyrosyl-regulated proteins. For example, activation of the insulin receptor results in the association of Syp with tyrosine-phosphorylated insulin receptor substrate 1, a protein participating in the insulin receptor signaling pathway [77०]. In addition, the proximal PTP may dephosphorylate and inactivate GFRs, thus terminating signal transduction. It is important to realize, however, that these two models may not be mutually exclusive

A third mechanism of SH2-PTP-mediated GFR signal transduction has been suggested by more recent results. In this model, the SH2 domains facilitate PTP-GFR interaction, whereupon the PTP is subsequently tyrosine-phosphorylated. The phosphorylated PTP could then interact with other $\mathrm{SH} 2$-containing proteins in signal transduction. In addition, tyrosine phosphorylation may increase PTP catalytic activity, potentially increasing the dephosphorylation of downstream effector molecules. Both Syp and PTP1D were shown to associate in vivo with activated PDGF and EGF receptors $\left[68^{\circ}, 69^{\circ} \cdot\right]$. Both PTT's failed to dephosphorylate the GFR, but were themselves tyrosine-phosphorylated. Phosphorylation of SH2-PTPs may be required for interaction with receptor tyrosine kinases and other signaling molecules $\left[68^{\circ}, 69^{\circ}, 76^{\circ}, 78^{\circ}\right]$. In the case of
PTP1D, phosphorylation is correlated with a small increase in PTP catalytic activity in vitro [69.0]. These findings indicate that SH2-PTPs may interact with PTKs, not simply to inactivate the GFR, but rather to work in concert with the GFR to regulate the phosphorylation state of signal transduction effector molecules.

\section{Nuclear-targeting domains}

Recently, several PTPs were shown to localize to the nucleus $\left[46^{\circ}, 79^{\circ}\right]$, which is intriguing given the suggested functional role of PTT's in cell cycle regulation and gene transcription $\left[15^{\circ}, 16,26^{\circ}, 27^{\circ}\right]$. In the case of the Drosopbila PTP DPTI 61 F, alternative splicing can produce two different carboxy-terminal zip codes directing the PTP to alternative locations [79']. Expression of each alternatively spliced form in COS-1 cells indicated that the form possessing a highly basic 11 amino acid carboxyl terminus was directed to the nucleus. The other DPTP61F species, containing a carboxy-terminal splice of 24 hydrophobic amino acids, was localized to a 'reticular' network and mitochondria-like organelles within the cell. The substrate specificities of the nuclear and membrane PTPs were indistinguishable, as expected, since they share the identical catalytic domain. This underlines the fact that subcellular location can define and restrict the substrate specificity of PTP'ases within the cell.

\section{Endoplasmic reticulum-targeting domains}

PTI'1B was originally purified from placental tissue as a soluble $39 \mathrm{kDa}$ protein [80]. However, the molecular cloning of rat and human PTT'1B predicted a $50 \mathrm{kDa}$ protein containing a hydrophobic carboxyl terminus $[81,82]$. Frangioni et al. [44] and Woodford-Thomas and co-workers [45'] showed that full length $\mathrm{P}^{\mathrm{T}} \mathrm{TP}^{\mathrm{P}} 1 \mathrm{~B}$ is normally localized to the endoplasmic reticulum in cells and that this localization is dictated by the carboxy-terminal 35 amino acids. Expression of carboxy-terminal truncated PTP1B results in a soluble enzyme. PTP1B can be released from the endoplasmic reticulum particulate fraction by trypsinization. The targeting of PTP's to the endoplasmic reticulum via their hydrophobic carboxyl terninus may result in limited substrate availability and act to keep PTP's in reserve until a cellular stimulus induces translocation of the PTP to the cytoplasm by carboxy-terminal proteolysis. Such an agonist-mediated stimulation of proteolysis and subsequent release of soluble PTP is observed in platelets [83"]. Activation of platelets by mixing, thrombin, or antibody engagement of the fibrinogen receptor gpIIb-IIIa, results in the activation of calpain, a calcium-dependent neutral protease. Activated calpain then cleaves PTT1B between its catalytic domain and its membrane-anchoring carboxyl terminus, resulting in a soluble PTP. The cleavage of PTP1B correlates with irreversible platelet aggregation [83०]. In addition, cleavage and subcellular relocation of PTP1B results in a twofold stimulation of its enzymatic activity and an altered pattern of phosphotyrosyl-substrate dephosphorylation [83०]. 


\section{Dual specificity tyrosine/serine protein phosphatases}

The first member of the class of dual specificity PTPS was identified in vaccinia virus [84]. This phosphatase, VH1, is a small $(20 \mathrm{kDa})$ soluble phosphatase (Fig. 2) that dephosphorylates both phosphotyrosine- and phosphoserine-containing substrates. VH1-like phosphatases have also been identified in smallpox variola virus, several orthopoxviruses and baculovirus [85]. In mammals, several VH1-like phosphatases have been cloned and shown to be induced as immediate-early genes. The synthesis of human T-cell PAC-1 [79॰], human CL100 [86] and the mouse homolog 3CH134 [20"] is induced by serum growth factors and oxidative or heat stress. In addition, a yeast VH1-like phosphatase has been shown to be induced upon nitrogen starvation [87].

Serum growth factors activate transmembrane protein tyrosine kinases [88]. Mitogen-activated protein kinase (MAP kinase) has been shown to be a major component of the signaling pathway involved in transducing the signal from activated PTKs to downstream effector molecules [89]. MAP kinase (p42) is activated by phosphorylation on Thr183 and Tyr 185 by MAl' kinase kinase [90]. The dual specificity phosphatases appear to dephosphorylate activated MAP kinase. Transcription of $3 \mathrm{CH} 134$ VH1-like phosphatase is rapidly induced by mitogenic stimulation, and synthesis occurs within the first hour [20']. $3 \mathrm{CH} 134$ dephosphorylates Thr183 and Tyr185 on activated MAP kinase both in vitro and in vivo [91•0]. In serum-stimulated fibroblasts, the inactivation of MAP kinase coincides with the new synthesis of $3 \mathrm{CH} 134\left[91^{\bullet \bullet}\right.$. Expression of $3 \mathrm{CH} 134$ in COS cells blocks serum-stimulation of MAP kinase, while the expression of a catalytically inactive $3 \mathrm{CH} 134$ augments MAP kinase phosphorylation. In addition, inactive $3 \mathrm{CH} 134$ can be immunoprecipitated with phosphorylated $\mathrm{MAl}^{\mathrm{P}}$ kinase demonstrating a physical interaction [91•0. These findings suggest that $3 \mathrm{CH} 134$ may be the physiological MAP kinase phosphate.

\section{Conclusions}

With the recent characterization of receptor-like PTP homophilic interactions, investigators can begin to approach the problem of understanding how these catalysts regulate signal processing during cell-cell contact. In addition, the characterization of intracellular PTP targeting domains will allow researchers to begin to determine how the substrate specificity of these enzymes is controlled. Characterization of targeting domains will also provide clues about PTP localization and function in the cellular landscape.

\section{Acknowledgements}

We wish to thank our colleagues Randy Stone and Zhong-Yin Zhang for their helpful comments in review of this manuscript. This work was supported in part by grants from the National Institutes of Health and the Walther Cancer Institute. Robert J Mourey is a Bristol-Myers Squibb Pharmaceutical Research Institute Fellow of the Life Sciences Research Foundation.

\section{References and recommended reading}

Papers of particular interest, published within the annual period of review, have been highlighted as:

- of special interest

-. of outstanding interest

1. TONKS NK, Funt AJ, GEBBink MFBG, SUN H, YANG Q: Signal -. Transduction and Protein Tyrosine Dephosphorylation. Adv Second Messenger Phosphoprotein Res 1993, 28:203-210.

An excellent review of the role that PTPs play in signal transcluction systems.

2. TONKS NK, YANG Q, FLINT AJ, GFibisink MFBB, FRANZA BR

- JR, Hill. DE, Sun H, Braloy-Kalnay S: Protein Tyrosine Phosphatases: the Problems of a Growing Family. Cold Spring Harb Symp Quant Biol 1993, 57:87-94.

A short review describing the properties of both intracellular and receptor-like PTPs. The authors discuss the homology of several receptor-like PTPs to cell adhesion molecules and the functional implications.

3. WAlTON KM, DIXON JE: Protein Tyrosine Phosphatases. -. Annu Rev Biocbem 1993, 62:101-120.

A thorough review detailing the structure and function of intracellular and receptor-like PTPs, their catalytic domains and their biological roles.

4. LaForgia S, MORSE B, LeVy J, BarnfaA G, CANNIZ-Westion La, Harkis CC, Drabkin $H$, pattikson D, Croce CM, SChlessinger J, Huebner K: Receptor Protein Tyrosine Phosphatase $\gamma$ is a Candidate Tumor Suppressor Gene at Human Chromosome Region 3p21. Proc Natl Acad Sci USA 1991, 88:5036-5040.

5. WOODFORD-THOMAS TA, RHODES JD, DIXON JE: Expression of a Protein Tyrosine Phosphatase in Normal and vSrc-Transformed Mouse 3T3 Fibroblasts. J Cell Btol 1992, 117:401-414.

6. Ruggiero M, Pazzagli C, rugacci S, magnelli l, raugel

- G, Berti a, Chiarugi vp, pierce jH, Camici g, ramponi G: Negative Growth Control by a Novel Low $M^{r}$ Phosphotyrosine Protein Phosphatase in Normal and Transformed Cells. FEBS Lett 1993, 326:294-298.

An interesting report describing the ability of an overexpressed liver PTP to reverse malignant growth in v-erhB, v-srcor v-raftransformed fibroblasts.

7. SRIDHAR TS, SWARUP G, KHAR A: Downregulation of Phospho-Tyrosine Phosphatases in a Macrophage Tumor. FEBS Lett 1993, 326:75-79.

8. TOMASKA L, RESNICK RJ: Involvement of a Phosphotyrosine Protein Phosphatase in the Suppression of Platelet-Derived Growth Factor Receptor Autophosphorylation in rastrans. formed Cells. Biocbem J 1993, 293:215-221.

9. ZANDER NF, COOL DE, DILTL CD, ROHRSCHNEIDER LR, KREBS EG, FISCHER EH: Suppression of v-fms-Induced Transformation by Overexpression of a Truncated T-Cell Protein Tyrosine Phosphatase. Oncogene 1993, 8:1175-1182.

10. JULIANO RL, HASKILL S: Signal Transduction from the Extra-. cellular Matrix. J Cell Blol 1993, 120:577-585. 
A general review of integrin-mediated signal transduction and the role of the extracellular matrix in cell differentiation. The authors discuss how this system parallels growth factor receptor signaling pathways and the potential points of intersection.

11. ROMER LH, BURRIDGe K, TURNer CE: Signaling Between the - Extracellular Matrix and the Cytoskeleton: Tyrosine Phosphorylation and Focal Adhesion Assembly. Cold Spring Harb Symp Qtiant Biol 1993, 57:193-202.

This study reports the identification of two tyrosine phosphorylatedfocal adhesion cytoskeletal components, pp125fak and paxillin, that are phosphorylated cluring extracellular matrix-mediated cellular adhesion. Tyrosine phosphorylation is implicated as an important step in the events that link cell-extracellular matrix interactions to cytoskeletal organization.

12. Howard PK, SEFTON BM, FIRTEL RA: Analysis of a Spatially -• Regulated Tyrosine Phosphatase Identifies Tyrosine Phosphorylation as a Key Regulatory Pathway in Dictyostelium. Cell 1992, 71:637-647.

An example of the importance of PTPs in regulation and development. PTP1 gene disruption or overexpression leads to severe morphological defects.

13. Keegan K, Hal.eguua S: Signal Transduction Pathways in Neuronal Differentiation. Curr Opin Neurobiol 1993, 3:14-19.

14. Shultz LD, SChWEITZER PA, RAjAN TV, YI T, IHLE JN, -. MATTHEWS RJ, THOMAS ML, BitER DR: Mutations at the Murine motbeaten Locus are Within the Hematopoietic Cell Protein Tyrosine Phosphatase (Hcpb) Gene. Cell 1993, 73:1445-1454.

This paper describes a specific defect in a PTP gene resulting in a phenotype where mice develop systemic autoimmune disease. These findings provide the first animal model of a PTP gene disruption.

15. Millar JBA, Russell P, Dixon JE, Guan KL: Negative Regu- lation of Mitosis by Two Functionally Overlapping PTPases in Fission Yeast. EMBO J 1992, 11:4943-4952.

This study reports the identification of a yeast PTP that, together with another PTP (pypl), inhibits the onset of mitosis. This novel discovery reveals a role for PTPs in mitotic control.

16. Ottulie S, Chernoff J, hannig G, hoffman CS, Erukson RI: The Fission Yeast Genes pyp1+ and pyp2+ Encode Protein Tyrosine Phosphatases that Negatively Regulate Mitosis. Mol Cell Biol 1992, 12:5571-5580.

17. MAEDA T, TSAI AYM, SAITO H: Mutations in a Protein - Tyrosine Phosphatase Gene (PTP2) and a Protein Serine/Threonine Phosphatase Gene (PTC1) Cause a Synthetic Growth Defect in Saccbaromyces cerevistae. Mol Cell Biol 1993, 13:5408-5417.

A report demonstrating that growth regulation in yeast requires the proper functioning of two protein phosphatases, one tyrosine- and one threonine/serine-specific protein phosphatase.

18. KORETZKY GA: Role of the CD45 Tyrosine Phosphatase in - Signal Transduction in the Immune System. FASEB J 1993, $7: 420-426$.

A thoughtful review summarizing the evidence from several laboratories on how CD45 exerts a regulatory role in TCR-mediated signal transduction.

19. MOONEY RA, FReUND GG, WAY BA, BORDWELL KL: EX- pression of a Transmembrane Phosphotyrosine Phosphatase Inhibits Cellular Response to Platelet-Derived Growth Factor and Insulin-Like Growth Factor-1. J Biol Chem 1992, 267:23443-23446.

This paper demonstrates that hormone-dependent autophosphorylation of growth factor receptors, and the regulation of proximal and distal cellular responses to growth factors, can be modulated by the expression of the transmembrane PTP, CD45.

20. Charles CH, Sun H, lau LF, TONKS NK: The Growth - Factor-Inducible Immediate-Early Gene 3CH134 Encodes a Protein-Tyrosine-Phosphatase. Proc Natl Acad Sct USA 1993. 90:5292-5296.
The report of a growth factor-inducible PTP that is transcriptionally regulated and transiently expressed. This PTP dephosphorylates MAP kinase in vitro, suggesting a role in the receptor tyrosine kinase signal transduction cascade.

21. CREWS CM, ERIKSON RL: Extracellular Signals and Reversible - Protein Phosphorylation: What to Mek of It All. Cell 1993. 74:215-217.

A mini-review summarizing all of the known players in a mitogenactivated signal transduction pathway.

22. GRISWOI.D-PRR:NNER I, CARISIN CR, ROSNER MR: Mitogen-Activated Protein Kinase Regulates the Epidermal Growth Factor Receptor through Activation of a Tyrosine Phosphatase. $J$ Biol Chem 1993, 268:13050-13054.

23. HERNÁNDEZ-SOTOMAYOR SMT, ARTEAGA CL, SOler C CARPENTFR G: Epidermal Growth Factor Stimulates SubstrateSelective Protein-Tyrosine-Phosphatase Activity. Proc Natl Acad Sci USA 1993, 90:7691-7695.

24. RJjKSEN G, Vollter MCW, van ZOEl.EN EJJ: The Role of Pro tein Tyrosine Phosphatases in Density-Dependent Growth Control of Normal Rat Kidney Cells. FEBS Lett 1993, 322:83-87.

25. PAN MG, FLoRIO T, STORK PJS: G Protein Activation of a Hormone-Stimulated Phosphatase in Human Tumor Cells. Sclence 1992, 256:1215-1217.

26. David M, Romero G, Zhang ZY, Dixon Je, larner aC: -. In Vitro Activation of the Transcription Factor ISGF3 by Interferon- $\alpha$ Involves a Membrane-Associated Tyrosine Phosphatase and Tyrosine Kinase. J Biol Cbem 1993. 268:6593-6599.

This paper reports the novel finding that the interferon- $\alpha$ signal transduction cascade involves both a membrane PTP and a tyrosine kinase. In addition, a second PTP participates by dephosphorylating a transcription complex in the nucleus, thereby inactivating transcription.

27. Igarashi K, David M, Finiloom DS, larner aC: In Vitmo

- Activation of the Transcription Factor $\mu$ Interferon Activation Factor by $\gamma$ Interferon: Evidence for a Tyrosine Phosphatase/Kinase Signaling Cascade. Mol Cell Biol 1993, 13:1634-1640.

Reports the first evidence for an interferon $\gamma$-regulated tyrosine phosphatase and tyrosine kinase signaling cascade that activates transcription of early response genes.

28. Zhang Z-Y, Dixon JE: Protein Tyrosine Phosphatases: Mech-. anism of Catalysis and Substrate Specificity. Adv Enzymol 1994, in press.

A review detailing the current understanding of the mechanism of catalysis for PTPs. The amino acid residues important for PTP structure and catalysis and the determinants of substrate specificity are summarized.

29. GUAN KL, DixON JE: Evidence for Protein-Tyrosine-Phosphatase Catalysis Proceeding via a Cysteine-Phosphate In termediate. J Biol Chem 1991, 266:17026-17030.

30. TAN X, STOVER DR, WALSH KA: Demonstration of Protein - Tyrosine Phosphatase Activity in the Second of Two Homo logous Domains of CD45. J Biol Chem 1993, 268:6835-6838.

This report refutes the long-held hypothesis that the second PTP catalytic domain in receptor-like PTPs is inactive. This paper suggests that the second PTP domain can function catalytically.

31. Kaplan R, morse B, hueisner $K$, Croce $C$, howk R, ravera M, RuCCA G, JAY'e M, SChlessinger J: Cloning of Three Hu man Tyrosine Phosphatases Reveals a Multigene Family of Receptor-Linked Protein-Tyrosine-Phosphatases Expressed in Brain. Proc Nall Acad SCi USA 1990, 87:7000-7004.

32. Yang $X$, SeOW KT, BahRI SM, OON SH, ChIa W: Two Drosopblla Receptor-Like Tyrosine Phosphatase Genes Are Expressed in a Subset of Developing Axons and Pioneer Neurons in the Embryonic CNS. Cell 1991, 67:661-673.

33. TIAN SS, TSOULFAS P, Zinn K: Three Receptor-Linked Pro tein Phosphatases are Selectively Expressed on Central Ner- 
vous System Axons in the Drosopbila Embryo. Cell 1991, 67:675-685.

34. Charbonneau H, tonks NK, Walsh Ka, Fischer eH: The Leukocyte Common Antigen (CD45): a Putative ReceptorLinked Protein Tyrosine Phosphatase. Proc Natl Acad Sct USA 1988, 85:7182-7186.

35. Streuli M, Krueger NX, Hall LR, Schlossiman SF, Sato h: A New Member of the Immunoglobulin Superfamily that has a Cytoplasmic Region Homologous to the Leukocyte Common Antigen. $J$ Exp Med 1988, 168:1523-1530.

36. Gebbink MF, van Eitten I, Hateboer $G$, Suljkerbujjk $k$,

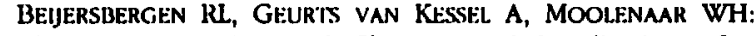
Cloning. Expression and Chromosomal Localization of a New Putative Receptor-Like Protein Tyrosine Phosphatase. FLBBS Lelt 1991, 290:123-130.

37. Jiang YP, Wang $\mathrm{H}$, D'Eustachio P, Musacchio JM, - SCHLESSINGer J, SAP J: Cloning and Characterization of RPTP $\kappa$, a New Member of the Receptor Protein Tyrosine Phosphatase Family with a Proteolytically Cleaved Cellular Adhesion Molecule-Like Extracellular Region. Mol Cell Biol 1993, 13:2942-2951.

Describes the cloning of a receptor-like PTP that defines the PTP subclass having homology to cell adhesion molecules. Members of this subclass are post-translationally modified by proteolytic cleavage of their extracellular domain and may play a role in cell-cell recognition, adhesion and development.

38. Harjharan IK, Chuang PT, Rubin GM: Cloning and Characterization of a Receptor-Class Phosphotyrosine Phosphatase Gene Expressed on Central Nervous System Axons in Drosopbila melanogaster. Proc Natl ACAd SCI USA 1991, 88:11266-11270.

39. KREUGER NX, STREULI M, SATTO H: Structural Diversity and Evolution of Human Receptor-Like Protein Tyrosine Phosphatases. $K M B O J$ 1990, 9:3241-3252.

40. KRUtGt:k NX, SANTU H: A Human Transmembrane ProteinTyrosine-Phosphatase, PTP $\zeta$, is Expressed in Brain and has an N-Terminal Receptor Domain Homologous to Carbonic Anhydrases. Proc Natl Acad Sci USA 1992, 89:7417-7421.

41. Barnea $G$, Silvennoinen $O$, shanan B, honegger aM,

- Canoll pD, déustachio P, morse B, levy JB, laforgia $S$, HUEBNER K l:T AL.: Identification of a Carbonic AnhydraseLike Domain in the Extracellular Region of RPTPy Detines a New Subfamily of Receptor Tyrosine Phosphatases. Mol Cell Biol 1993, 13:1497-1506.

This paper reports the cloning of a receptor-like PTP containing an extracellular domain with homology to carbonic anhydrase. Together with the identification of HPTP [ [40], these PTPs define a new subfamily of receptor-like PTPs. In addition, computer modeling indicates the carbonic anhydrase domain structure is retained in this PTP, although several residues required for catalysis are missing. suggesting another function for this domain.

42. BRADY-KAINAY SM, FUNT AJ, TONKS NK: Homophilic Binding -. of PTP $\mu$, a Receptor-Type Protein Tyrosine Phosphatase, Can Mediate Cell-Cell Aggregation. J Cell Biol 1993, 122:961-972. A rigorous piece of work identifying the first 'ligand' for receptorlike PTPs. This paper demonstrates the ability of PTP $\mu$ to mediate cell-cell homophilic adhesion independently of its PTP catalytic activity.

43. GEIBBINK MFBG, ZONDAG GCM, WUIBISOI:TS RW,

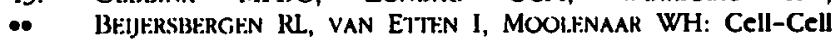
Adhesion Mediated by a Receptor-Like Protein Tyrosine Phosphatase. J Btol Chem 1993, 268:16101-16104.

An excellent communication reporting the identification of PTP $\mu$ as its own ligand, facilitating homophilic cell-cell adhesion.

44. Frangioni JV, Beahm PH, Shitrin V, Jost CA, NHei. BG: The Nontransmembrane Tyrosine Phosphatase PTP-1B Localizes to the Endoplasmic Reticulum via Its 35 Amino Acid C. Terminal Sequence. Cell 1992, 68:545-560.
45. MAURO LJ, WOODFORd-ThOMAS TA, POT DA, TAPAROWSKY - EJ, DIXON JE: Targeting of an Intracellular Tyrosine Phosphatase: Mechanisms and Functional Relevance. Adv Prot Phosphatases 1993, 7:393-411.

A thorough review describing the role of the $C$-terminal extension in targeting PTP1 to the endoplasmic reticulum and its functional significance.

46. MClaughun S, Dixon JE: Atternative Splicing Gives Rise to - a Nuclear Protein Tyrosine Phosphatase in Drosopblla. $J$ Biol Chem 1993, 268:6839-6842.

A novel finding demonstrating that intracellular targeting of PTPs can be dictated by alternative splicing, which may add carboxy-terminal extensions directing PTPs to cytoplasmic membranes or the nucleus.

47. YANG $Q$, CO D, SOMmerCORN J, TONKS NK: Cloning and - Expression of PTP-PEST. J Biol Chem 1993, 268:6622-6628. The cloning of a novel PTP containing a carboxy-terminal PEST sequence that potentially determines a shon intracellular half-life.

48. GU MX, YORK JD, WARShawSKY I, Majerus PW: Identification. Cloning, and Expression of a Cytosolic Megakaryocyte Protein-Tyrosine-Phosphatase with Sequence Homology to Cytoskeletal Protein 4.1. Proc Natl Acad Sci USA 1991, 88:5867-5871.

49. YANG Q, TONKS NK: Isolation of a cDNA Clone Encoding a Human Protein-Tyrosine Phosphatase with Homology to the Cytoskeletal-Associated Proteins Band 4.1, Ezrin, and Talin. Proc Natl Acad Sct USA 1991, 88:5949-5953.

50. Zhao Z, Bouchard P, Diltz CD, Shen SH, Fischer EH: Purification and Characterization of a Protein Tyrosine Phosphatase Containing SH2 Domains. J Biol Cbem 1993, 268:2816-2820.

51. FReiman JRM, PLUTZKY J, NeEl BJ: Identification of a Human

- Src Homology 2-Containing Protein-Tyrosine-Phosphatase: a Putative Homolog of Drosopblla Corkscrew. Proc Natl Acad Sci USA 1992, 89:11239-11243.

The identification and cloning of an SH2-containing PTP that may be the mammalian homolog of corkscrew, a member of the torso receptor tyrosine kinase signal transduction pathway in Drasopbila.

52. RANKIN BM, YOCUM SA, MITIIER RS, KIENER PA: Stimulation of Tyrosine Phosphorylation and Calcium Mobilization by FCy Receptor Cross-Linking: Regulation by the Phosphotyrosine Phosphatase CD45. J Immunol 1993, 150:605-616.

53. DESA DM, SAP J, Schlessinger J, WEIss A: Ligand-Mediated -. Negative Regulation of a Chimeric Transmembrane Receptor Tyrosine Phosphatase. Cell 1993, 73:541-554.

A classic paper demonstrating that ligand binding may facilitate dimerization of a receptor-like PTP, thereby negatively regulating its activity. The data suggest the novel idea that ligand-mediated regulation of receptor-PTPs may have mechanistic similarities with receptor tyrosine kinases.

54. Stover DR, Charbonneau H, TONKS NK, Walsh Ka: ProteinTyrosine-Phosphatase CD45 Is Phosphorylated Transiently on Tyrosine Upon Activation of Jurkat T Cells. Proc Natl Acad SCI USA 1991, 88:7704-7707.

55. Lammers R, Van Obiberghen E, Ballotin $k$, Schlessinger J, Ul.LRICH A: Transphosphorylation as a Possible Mechanism for Insulin and Epidermal Growth Factor Receptor Activation. J Biol Cbem 1990, 265:16886-16890.

56. BeCKmann G, BORK P: An Adhesive Domain Detected in - Functionally Diverse Receptors. Trends Biocbem Sci 1993, $18: 40-41$.

A report of a consensus motif that is associated with several adhesive proteins.

57. Euglenraam F: Things Start Getting Sticky for a Cell Surface -. Enzyme. Science 1993, 261:833.

A 'research news' article describing results from several laboratories that PTP $\mu$ and PTPK mediate cell-cell adhesion through homophilic interactions.

58. Levy JB, Canoll. PD, Silvennoinen O, Barnia G, Morst: B, - honegger am, huang JT, cannizzaro la, park sh, Druck 
T, ET AL: The Cloning of a Receptor-Type Protein Tyrosine Phosphatase Expressed in the Central Nervous System. $J$ Biol Chem 1993, 268:10573-10581.

This paper describes the identification of a carbonic anhydraselike domain in a brain-specific transmembrane PTP. This PTP is developmentally-expressed and may therefore play a role in central nervous system development.

59. Guan K-L, Dixon JE: Protein Tyrosine Phosphatase Activity of an Essential Virulence Determinant in Yersinia. Science $1990,249: 553-556$.

60. NILES EG, SETO J: vaccinia Virus Gene D8 Encodes a Virion Transmembrane Protein. / Virol 1988, 62:3772-3778.

61. MAA J-S, RODRIQUEZ JF, EsItiBAN M: Structural and Functional Characterization of a Cell Surface Binding Protein of vaccinia Virus. J Biol Chem 1990, 265:1569-1577.

62. FANTT. WJ, JOHNSON DE, WILIIAMS LT: Signaling by Receptor -. Tyrosine Kinases. A'nnu Rev Biocbem 1993, 62:453-481. An excellent review of recent biochemical and cellular studies detailing signal transduction by receptor tyrosine kinases and their signaling pathway components. A thorough description of the receptor tyrosine kinase subfamilies is discussed.

63. SChlfessinger J, Mohammadi M, Margolis B, Ullaich A: Role of SH2-Containing Proteins in Cellular Signaling by Receptor Tyrosine Kinases. Cold Spring Harb Symp Quant Biol 1992, 57:67-74.

This paper presents models of how SH2-containing proteins participate in receptor tyrosine kinase signaling pathways. A current list of SH2-containing proteins and their functions is discussed.

64. Felder S, ZhOU M, Hu P, URfÑa J, Uli.rich A, Chaudhur M, WhITE M, Shotison SE, SCHLESSINGier J: SH2 Domains Exhibit High-Affinity Binding to Tyrosine-Phosphorylated Peptides Yet Also Exhibit Rapid Dissociation and Exchange. Mol Cell Biol 1993, 13:1449-1455.

65. Pet D, NeEL BG, WAlSH CT: Overexpression, Puritication, and Characterization of SHPTP1, a Src Homology 2-Containing Protein-Tyrosine-Phosphatase. Proc Nall Acad SCI USA 1993, 90:1092-1096.

66. Y1 T, Cleveland JL, IHLE JN: Protein Tyrosine Phosphatase Containing SH2 Domains: Characterization, Preferential Expression in Hematopoietic Cells, and Localization to Hurnan Chromosome 12p12-p13. Mol Cell Biol 1992, 12:836-846.

67. Shen SH, BAstitin L, POSNik BI, Chreinen P: A Protein-Tyrosine Phosphatase with Sequence Similarity to the $\mathrm{SH} 2$ Domain of the Protein-Tyrosine Kinases. Nature 1991, 352:736-739.

68. FENG G, HUI C, PAwsON T: SH2-Containing Phosphotyrosine - Phosphatase as a Target of Protein-Tyrosine Kinases. Science 1993, 259:1607-1611.

This paper reports the identification of the SH2-containing PTP Syp, and describes its in vivo association with activated epidermal and platelet-derived growth factor receptors. The function of Syp in mammalian embryonic development and its role as a target for both receptor and non-receptor tyrosine kinases is discussed.

69. VOGEL. W, LAMmirs R, HUANG J, UllRich A: Activation of a - Phosphotyrosine Phosphatase by Tyrosine Phosphorylation. Science 1993, 259:1611-1614.

Describes the identification of an SH2-containing PTP, PTP1D, and shows its in vivo association and phosphorylation (as in [68.]). The PTP identified in [680] is a C-terminal splice variant of PTP1D. The novel finding, that the physical interaction of a PTP with a protein tyrosine kinase results in PTPase activity modulation, is presented.

70. Ahmad S, Banville: D, Zhao Z, Fischir EH, Shen S-H: A Widely Expressed Human Protein-Tyrosine Phosphatase Containing Src Homology 2 Domains. Proc Natl Acad Sci USA 1993, 90:2197-2201.

71. ADACHI M, SEKIYA M, MIYACHI T, Maisuno K, HinOda $Y$ IMA K, YACHI A: Molecular Cloning of a Novel Protein-
Tyrosine Phosphatase SH-PTP3 with Sequence Similarity to the Src-Homology Region 2. FEBS Lett 1992, 314:335-339.

72. TSUI HW, SIMINOVITCH KA, DE SOUSA L, TSUI FWL: motbe aten and viable Mice have Mutations in the Haematopoietic Cell Phosphatase Gene. Nature Genet 1993, 4:124-129.

73. Perkins la, Larsen I, Perrimon N: corkscrew Encodes a Pi- $\quad$ tative Protein Tyrosine Phosphatase that Functions to Transduce the Terminal Signal from the Receptor Tyrosine Kinase torso. Cell 1992, 70:225-236.

74. Ambrosio L, Mahowald A, Perrimon N: Requirement of the Drosopbilla raf Homologue for torso Function. Natture 1989, 342:288-290.

75. Sprenger F, Stevens LM, Nusslein-Volhard C: The Drosopbila Gene torso Encodes a Putative Receptor Tyrosine Kinase. Nature 1989, 338:478-483.

76. LECHI.EIDER RJ, Frfigan RM JR, Neti. BG: Tyrosyl Phosphory- lation and Growth Factor Receptor Association of the Human corkscrew Homologue, SH-PTP2. J Biol Chem 1993, 268:13434-13438.

This paper provides evidence for the association and subsequent tyrosine phosphorylation of SH-PTP2 with activated growth factor receptors. Several models of SH-PTP signaling are presented.

77. KUHNE MR, PAwson T, LIENhard GE, Feng G-S: The In- $\quad$ sulin Receptor Substrate 1 Associates with the SH2-Containing Phosphotyrosine Phosphatase Syp. J Biol Chem 1993, 268:11479-11481.

A report describing the association of an $\mathrm{SH} 2$-containing PTP with an insulin receptor pathway signaling component. These findings suggest that tyrosine phosphorylated-IRS-1 may act as a docking protein for $\mathrm{SH} 2$-containing proteins, recruiting these proteins for insulin signaling.

78. YEUNG YG, BeRG KL, PIXI.FY FJ, ANGELETTI RH, STANLFY ER: Protein Tyrosine Posphatase-lc Is Rapidly Phosphorylated in Tyrosine in Macrophages in Response to Colony Stimulating Factor-1. J Biol Chem 1992, 267:23447-23450.

This communication describes the rapid, growth factor-induced tyrosine phosphorylation of the intracellular phosphatase, PTP-1C, implicating its role in an early event in growth factor signal transduction.

79. Rohan PJ, Davis P, moskaluk Ca, Kearns M, Kritzzsch H - SIFBenLIST U, KFll.Y K: PAC-1: a Mitogen-Induced Nuclear Protein Tyrosine Phosphatase. Science 1993, 259:1763-1766. Describes the cloning of a nuclear-localized PTP which possesses dual specificity for phosphotyrosyl- and phosphoseryl-containing substrates.

80. TONKS NK, DILTZ CD, FISCHER EH: Purification of the Major Protein-Tyrosine-Phosphatases of Human Placenta. J Btol Chem 1988, 263:6722-6730.

81. Guan KL, haun RS, WAison SJ, GtahleN RL, DixON JE: Cloning and Expression of a Protein-Tyrosine-Phosphatase. Proc Natl Acad SCi USA 1990, 87:1501-1505.

82. Chernoff J, Schievella AR, Jost CA, Erikson RL, Neel BG: Cloning of a cDNA for a Major Human Protein-Tyrosine. Phosphatase. ProC Natl Acad SCI USA 1990, 87:2735-2739.

83. Frangioni JV, odja A, SMith M, salizman EW, Nefl. BG: - Calpain-Catalyzed Cleavage and Subcellular Relocation of Protein Phosphotyrosine Phosphatase 1B (PTP-1B) in Human Platelets. EMBO J 1993, 12:4843-4856.

This paper describes the agonist-mediated stimulation of PTP1B proreolytic cleavage by calpain, resulting in the relocation of PTP1B to the cytosol, a small increase in catalytic activity, and an alteration in the pattern of tyrosyl phosphorylation.

84. GUAN K, BROYI.FS SS, DIXON JE: A Tyr/Ser Protein Phosphatase Encoded by Vaccinia Virus. Nature 1991, 350:359-362.

85. HAKES DJ, MaR'T7LL. KJ, ZHAO W-G, Massung RF, EsPOSITO JJ, DixON JE: A Protein Phosphatase Related to the Vaccinia Virus VHI is Encoded in the Genomes of Several Or- 
thopoxviruses and a Baculovirus. Proc Natl Acad SCi USA 1993, 90:4017-4021.

86. AlessI DR, SMYTHE C, KeYSE SM: The Human Cl100 Gene Encodes a Tyr/Thr-Protein Phosphatase which Potently and Specificially Inactivates MAP Kinase and Suppresses its Activation by Oncogenic Ras in Xenopus Oocyte Extracts. Oncogene 1993, 8:2015-2020.

87. Guan K, Hakes DJ, Wang Y, Park H-D, CoOper TG, Dixon JE: A Yeast Protein Phosphatase Related to the Vaccinia VHI Phosphatase is Induced by Nitrogen Starvation. Proc Natl Acad SCi USA 1992, 89:12175-12179.

88. UllRiCH A, SCHI.ESSINGER J: Signal Transduction by Receptors with Tyrosine Kinase Activity. Cell 1990, 61:203-212.

89. COBB MH, BOULTON TG, ROBBINS DJ: Extracellular SignalRegulated Kinases: ERKs in Progress. Cell Reg 1991, 2:965-978.

90. PaYNe DM, Rossomanido AJ, Martino P, Ekikson AK, HFr J-H, Shabanowitz J, Hunt DF, Weble MJ, SiUrgill.
TW: Identification of the Regulatory Phosphorylation Sites in pp42/Mitogen-Activated Protein Kinase (MAP Kinase). EMBO J 1991, 10:885-892.

91. SUN H, Charles CH, LAU L, TONKS NK: MKP-1 (3CH134), an -. Immediate Early Gene Product, is a Dual Specificity Phosphatase that Dephosphorylates MAP Kinase in Vlwo. Cell 1993, 75:487-493.

A report describing the in vitro and in vivo dephosphorylation of MAP kinase by the growth factor induced dual specificity phosphatase, $3 \mathrm{CH} 134$. The authors propose that $3 \mathrm{CH} 134$ is the physiological MAP kinase phosphatase.

RJ Mourey and JE Dixon, Department of Biological Chemistry, Medical School, Walther Cancer Institute, Medical Science I, University of Michigan, 1301 E. Catherine Street, Ann Arbor, Michigan 48109-0606, USA. 